\title{
PENYULUHAN SISTEM AUTOMASI BERBASIS MIKROKONTROLER ARDUINO UNO UNTUK SISWA-SISWI JURUSAN TEKNIK KOMPUTER JARINGAN DI SMK
}

\author{
Putri Dina Mardika ${ }^{1}$, Nilma ${ }^{2}$, Rahnita Nuzulah ${ }^{3}$ \\ Informatika, Fakultas Teknik Dan Ilmu Komputer, Universitas Indraprasta PGRI
}

\begin{abstract}
Abstrak
SMK Ganesa Satria merupakan sekolah yang telah terakreditasi A, begitupun dengan SMK YPPD merupakan sekolah yang telah terakreditasi A. SMK Ganesa Satria dan SMK YPPD, sudah lama berdiri di wilayah Kota Depok, memiliki guru yang berpengalaman dalam mengajar di bidangnya, dan memiliki beberapa jurusan di kedua sekolah tersebut. Pengabdian masyarakat ini diberikan untuk siswa - siswi jurusan Teknik Komputer Jaringan di kedua SMK tersebut. Memfokuskan mengenai penyuluhan sistem automasi berbasis mikrokontroller yang menggunakan Arduino Uno dengan memanfaatkan PIR (Passive Infra Red) Sensor sebagai sistem pendeteksi gerak pada suatu ruangan. Hasil yang diperoleh dari kegiatan ini cukup positif dan telah berjalan dengan baik, pihak mitra menyatakan timbul rasa ketertarikan dan antusias dalam upaya peningkatan pengetahuan dan kemampuan mengenal, mengetahui sistem automasi berbasis mikrokontroler arduino uno, serta mampu membuat sekaligus menjalan program yang diberikan dalam penyuluhan yang berkaitan dengan sistem automasi berbasis mikrokontroller Arduino Uno.
\end{abstract}

Kata Kunci : Penyuluhan, Pelatihan, Bahan Ajar, Mikrokontroller Arduino, PIR (Passive Infra Red) Sensor

\begin{abstract}
SMK Ganesa Satria is an accredited school A, as well as with SMK YPPD is a school that has been accredited A. SMK Ganesa Satria and SMK YPPD, has long standing in the area of Depok City, has a teacher who is experienced in teaching in his field, and has several majors in both schools. This community service is provided for students in the Computer Network Engineering department at both Vocational Schools. Focusing on extension of microcontroller based automation system using Arduino Uno by utilizing PIR (Passive Infra Red) Sensor as motion detection system in a room. The results obtained from this activity is quite positive and has been running well, the partners expressed aroused interest and enthusiasm in an effort to increase knowledge and knowing ability, knowing automation system based arduino uno microcontroller, and able to create as well as run the program given in the related extension with automation system based on Arduino Uno microcontroller.
\end{abstract}

Keywords: Counseling, Training, Teaching Materials, Arduino Microcontroller, PIR (Passive Infra Red) Sensors

Correspondence author: Putri Dina Mardika, putri.dinamardika@unindra.ac.id, Indonesia

\section{PENDAHULUAN}

Pendidikan adalah usaha sadar dan terencana untuk mewujudkan suasana belajar dan proses pembelajaran agar peserta didik secara aktif mengembangkan potensi dirinya untuk memiliki kekuatan spiritual keagamaan, pengendalian diri, kepribadian, 
kecerdasan, akhlak mulia, serta keterampilan yang diperlukan dirinya, masyarakat, bangsa dan negara.Sistem pendidikan nasional adalah keseluruhan komponen pendidikan yang saling terkait secara terpadu untuk mencapai tujuan pendidikan nasional.Anggota masyarakat yang mengabdikan diri dan diangkat untuk menunjang penyelenggaraan pendidikan disebut sebagai tenaga pendidik. Tenaga kependidikan yang berkualifikasi sebagai guru, dosen, konselor, pamong belajar, widyaiswara, tutor, instruktur, fasilitator, dan sebutan lain yang sesuai dengan kekhususannya, serta berpartisipasi dalam menyelenggarakan pendidikan.[1]

Tenaga pendidik khususnya dosen, dikatakan sebagai pendidik professional dan ilmuwan, yang artinya memiliki pengetahuan dan perilaku yang dikuasai dan diwujudkan dalam melaksanakan tugas utama seorang dosen dengan mentransformasikan melalui, pendidikan, penelitian, dan pengabdian kepada masyarakat. Untuk menjalankan amanah sebagaiamana tugas utama seorang dosen, yang salah satunya pengabdian kepada masyarakat, kegiatan ini dilakukan di kedua sekolah menengah kejuruan jurusan teknik komputer dan jaringan di kota depok.

Kurangnya pengetahuan dan pemahaman siswa - siswi sekolah menengah kejuruan baik di smk ganesa satria dan smk yppd tentang pemrograman mikrokontroler, khususnya mikrokontroler arduino uno. Oleh karena itu, tim abdimas merasa perlu memberikan bekal pengetahuan dengan memberikan dasar - dasar informasi mengenai mikrokontroler arduino uno kepada siswa - siswa sekolah mengah kejuruan khususnya di SMK Ganesa Satria dan SMK YPPD.

Adapun tujuan kegiatan dari abdimas ini adalah untuk menjalankan dan mewujudkan salah satu tugas serta tanggung jawab dari Tridarma Perguruan Tinggi dalam mengabdikan ilmu yang dimiliki bagi masyarakat dengan memberikan pengetahuan melaluipenyuluhan dan pelatihan kepada siswa- siswi sekolah menengah kejuruan di SMK Ganesa Satria dan SMK YPPD tentang mikrokontroler arduino uno.

\section{METODE PELAKSANAAN}

Pelaksanaan penyuluhan dilakukan di SMK Ganesa Satria yang berlokasi Kompleks Ganesa Satria, Jl. Merdeka Kelurahan Abadijaya, Kecamatan Sukmajaya, Kota Depok, Jawa Barat 16417. Penyuluhan ini di peruntukan bagi siswa dan siswi SMK Ganesa Satria dan SMK YPPD, dengan metode pelaksanaan sebagai berikut :

1. Melakukan kunjungan dengan kepala sekolah masing - masing, untuk menyampaikan maksud Tim Abdimas ke lokasi. Dan sasaran yang diberikan adalah siswa - siswi dari Sekolah SMK Ganesa Satria dan Sekolah SMK YPPD.

2. Tim abdimas menganalisa kebutuhan mitra, mengumpulkan bahan dan materi yang akan digunakan untuk penyuluhan kepada kedua sekolah.

3. Pelaksanaan abdimas.

4. Pelatihan diberikan kepadasiswa - siswi dari Sekolah SMK Ganesa Satria dan Sekolah SMK YPPDdilokasi yang sudah disiapkan oleh pihak Mitra Abdimas, yaitu di aula Sekolah SMK Ganesa Satria.

5. Pelaporan Kegiatan

6. Melakukan sejumlah analisa terhadap hasil kegiatan dan mengambil kesimpulan untuk dapat dilakukan perbaikan pada kegiatan abdimas selanjutnya. 


\section{HASIL DAN PEMBAHASAN}

1. Kegiatan Pendahuluan

a. Perizinan

Pada tanggal 17 April 2018 tim abdimas mengirim surat permohonan kepada mitra tentang pengadaan Penyuluhan Sistem Automasi Berbasis Mikrokontroler Arduino Uno untuk Siswa-Siswi Jurusan Teknik Komputer Jaringan di SMK Ganesa Satria dan SMK YPPD.

b. Pendataan Siswa-siswi Ganesa Satria dan SMK YPPD

Setelah mendapat izin dari pihak mitra, kemudian tim abdimas melakukaan pendataan siswa-siswi SMK jurusan teknik komputer jaringan untuk menindak lanjuti penyuluhan sistem automasi berbasis mikrokontroler arduino uno.

2. Observasi Lapangan (10 s/d 17 April 2018)

a. Pertemuan dengan Kepala sekolah SMK Ganesa Satria dan SMK YPPD

Kegiatan ini kami lakukan untuk menggali data dan informasi tentang siswasiswi dalam kemampuan mengetahui sistem automasi berbasis mikrokontroler arduino uno.

b. Analisi Permasalahan Mitra

Dari hasil temuan data dan informasi, dihasilkan kendala atau masalah dalam hal keterampilan dan penguasaan media pembelajaran sistem automasi berbasis mikrikontroler, sebagai berikut:

Kurangnya pengetahuan dan pemahaman siswa - siswi sekolah menengah kejuruan baik di SMK Ganesa Satria dan SMK YPPD tentang pemrograman mikrokontroler, khususnya mikrokontroler arduino uno.

c. Penyusunan Materi Penyuluhan

1) Memberikan pengetahuan awal tentang dasar dasar mikrokontroler arduino uno.

2) Memberikan salah satu contoh sistem automasi berbasis mikrokontroler.

3) Memberikan contoh pembuatan sistem automasi berbasis mikrokontroler.

4) Memberikan modul dan menjelaskan proses dan langkah-langkah tentang arduino uno.

5) Melakukan penyuluhan proses penggunaannaan arduino uno.

3. Realisasi Kegiatan Abdimas (2 Juni 2018)

a. Pemberian Materi

Tim pengabdian masyarakat memberikan materi tentang dasar-dasar media pembelajaran sistem automasi berbasis mikrokontroler untuk bahan pelajaran siswa-siswi jurusan teknik komputer jaringan dengan tujuan memberikan pengetahuan bahwa media pembelajaran sistem automasi berbasis mikrokontroler dapat digunakan siswa-siswi dalam pembelajaran teknik jaringan komputer di kelas.

Tim memberikan modul bagaimana cara penguasaan dan penggunaan sistem sutomasi berbasis mikrokontroler arduino uno.

b. Penyuluhan Sistem Automasi berbasis Mikrokontroler Arduino Uno Dengan dipandu modul yang telah kami berikan, maka kami memulai penyuluhan. Dengan metode penyuluhan satu pemateri menyampaikan di depan, sedangkan peserta penyuluhan mengikuti materi pada modul masing-masing. 

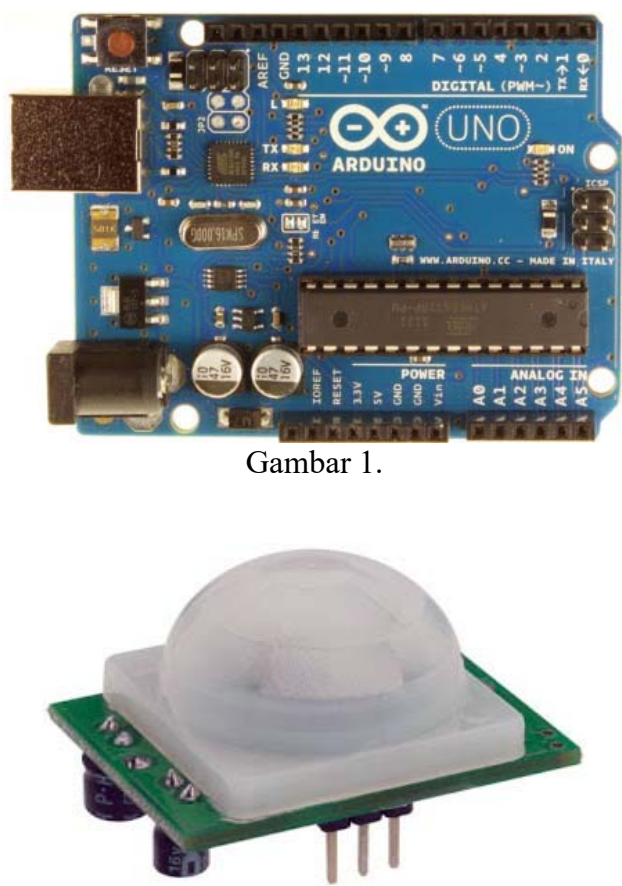

Gambar 2 .

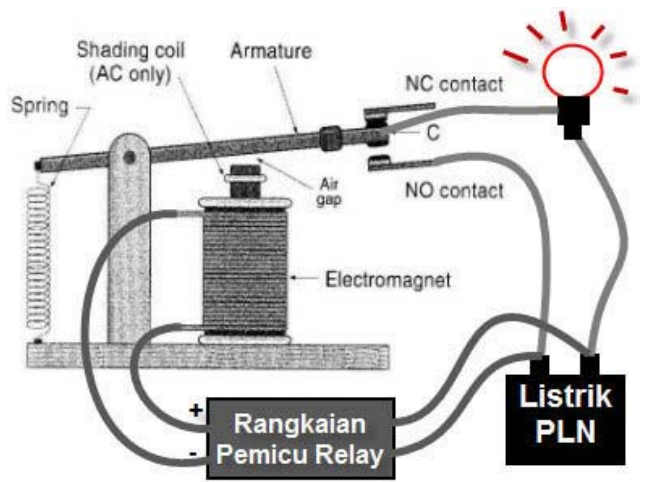

Gambar 3.

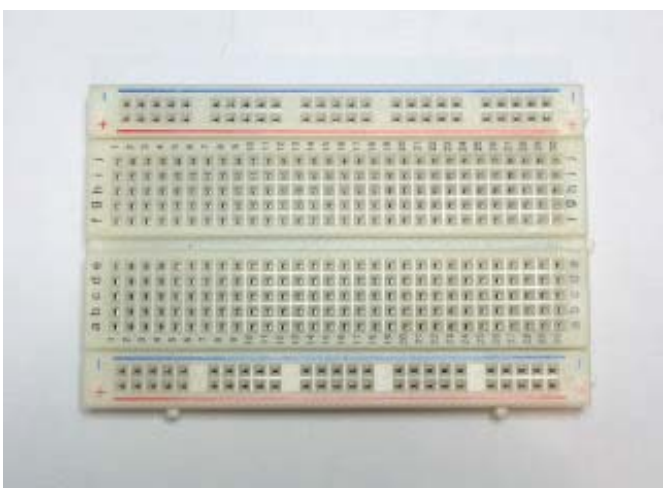

Gambar 4. 


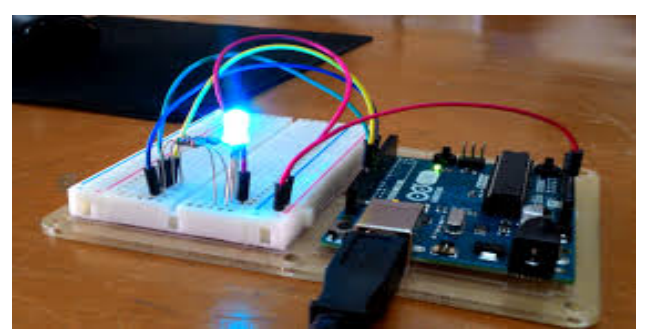

Gambar 5 .

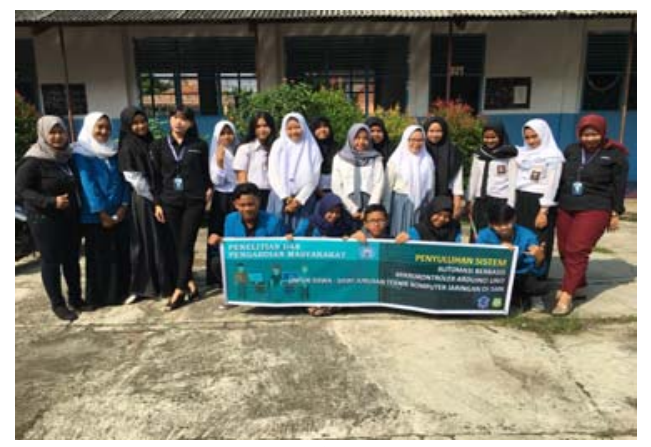

Gambar 7.

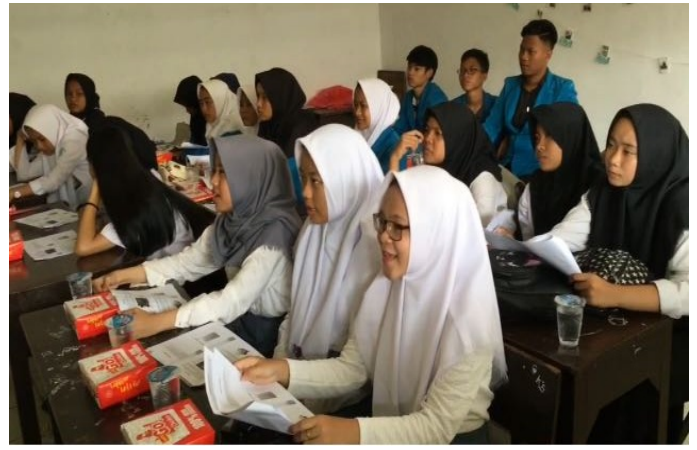

Gambar 8 .

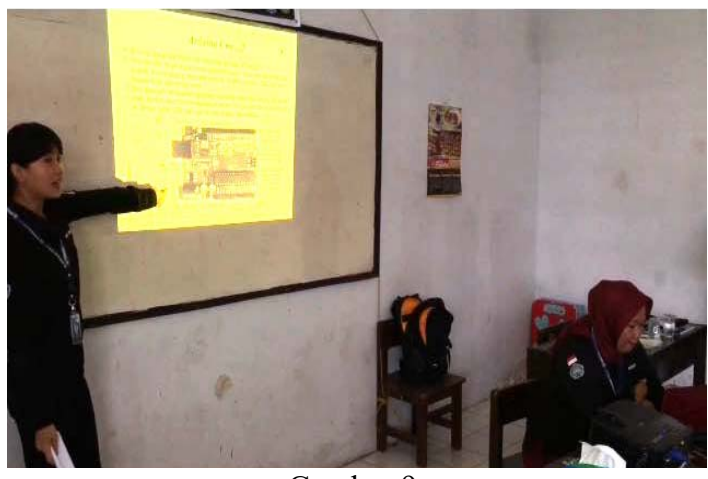

Gambar 9 . 


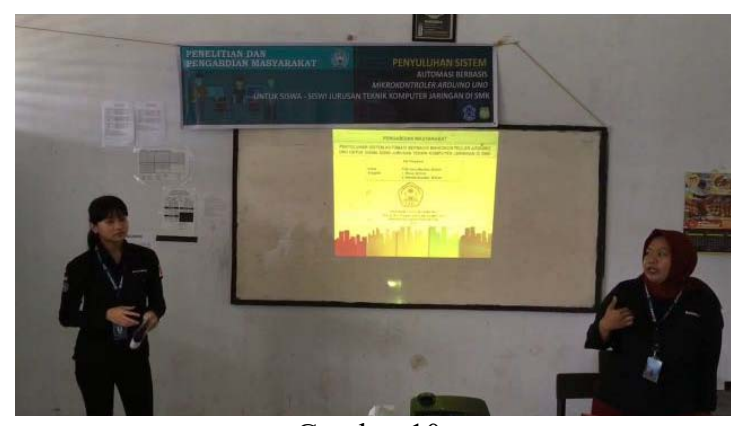

Gambar 10.

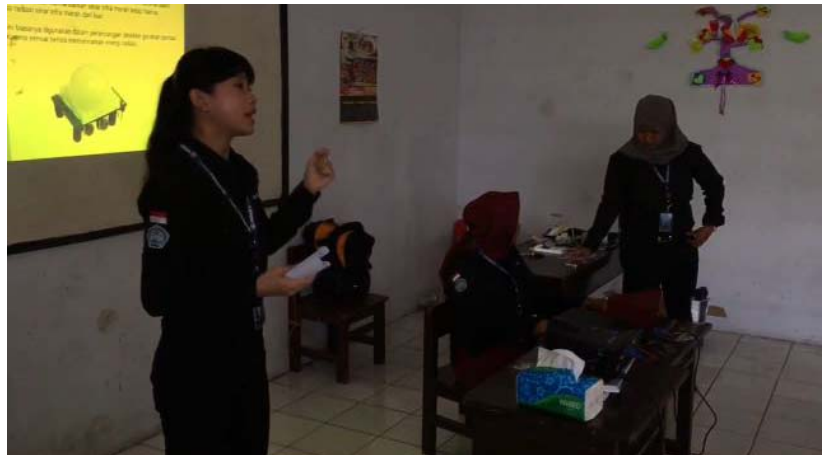

Gambar 11.

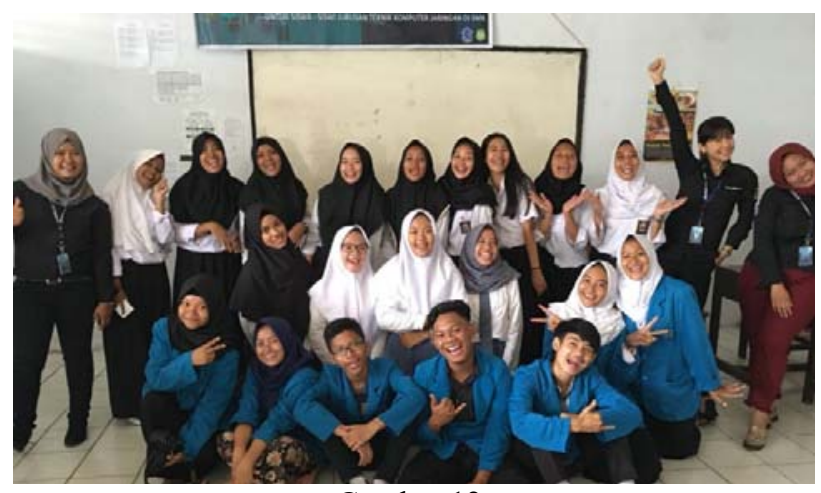

Gambar 12.

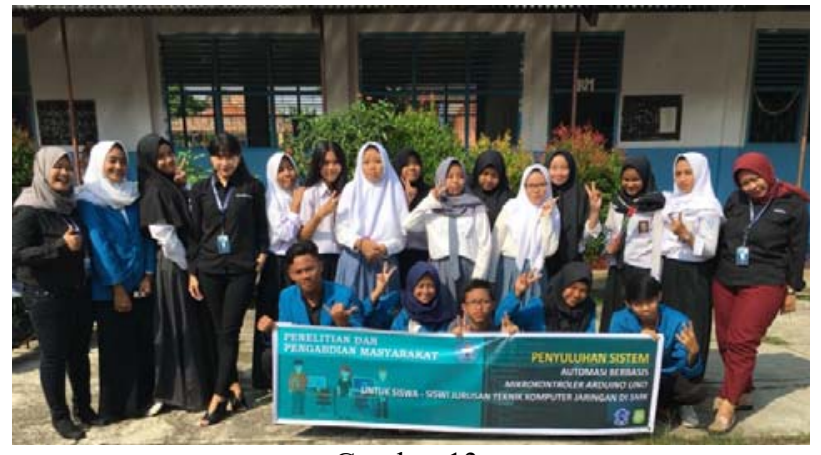

Gambar 13. 
Kegiatan penyuluhan dilaksanakan pada tanggal dengan target peserta penyuluhan mampu mengenal dan mengetahui sistem automasi berbasis mikrokontroler arduino uno.

\section{SIMPULAN}

Walaupun dirasa masih belum sepenuhnya mencapai target dan luaran yang diharapkan, namun kegiatan pengabdian masyarakat ini telah memberikan kontribusi yang positif bagi upaya peningkatan pengetahuan dan kemampuan dalam mengenal dan mengetahui sistem automasi berbasis mikrokontroler arduino uno. Kegiatan ini telah berjalan dengan baik dan dapat disimpulkan sebagai berikut:

1. Para siswa-siswi SMK Ganesa Satria dan SMK YPPD antusias dalam pelaksanaan kegiatan dan mulai timbul ketertarikan dalam mempelajari sistem automasi berbasis mikrokontroler berbasis arduino uno.

2. Para siswa-siswi SMK Ganesa Satria dan SMK YPPD mampu membuat dan menjalankan program dari penyuluhan yang diberikan menggunakan arduino uno yang berkaitan dengan sistem automasi.

\section{DAFTAR PUSTAKA}

UU Nomor 20 Tahun 2003 tentang Sistem Pendidikan Nasional pasal (13), pasal (14), pasal (15), pasal (17), pasal (18).

psmk.kemdikbud.go.id/1869/konsep-pembelajaran-di-sekolah-menemgah-kejuruan. 